\title{
Flow and Heat Transfer in a Newtonian Liquid with Temperature Dependent Properties over an Exponential Stretching Sheet
}

\author{
P. G. Siddheshwar ${ }^{1}$, G. N. Sekhar ${ }^{2}$ and A. S. Chethan ${ }^{3 \dagger}$ \\ ${ }^{1}$ Department of Mathematics, Bangalore University, Central College Campus,560 001, Bangalore, India \\ ${ }^{2}$ Department of Mathematics, BMS College of Engineering, Bangalore, 560 019, Karnataka, India \\ ${ }^{3}$ Department of Mathematics, BMS Institute of Technology, Bangalore, 560064 Karnataka, India \\ ${ }^{\dagger}$ Corresponding Author Email: as.chethan@gmail.com
}

(Received March 28, 2013; accepted May 28, 2013)

\begin{abstract}
The paper presents a study of a forced flow and heat transfer of an electrically conducting Newtonian fluid due to an exponentially stretching sheet. The governing coupled, non-linear, partial differential equations are converted into coupled, non-linear, ordinary differential equations by a similarity transformation and are solved numerically using shooting method. The influence of various parameters such as the Prandtl number, Chandrasekhar number, variable viscosity parameter, heat source (sink) parameter and suction/injection on velocity and temperature profiles are presented and discussed.
\end{abstract}

Keywords: Stretching sheet, Variable viscosity, Prandtl number, Chandrasekhar number, Shooting Method, Heat transport, Heat source.

\section{NOMENCLATURE}

$\begin{array}{ll}A, D & \text { prescribed constants } \\ C_{p} & \text { specific heat at constant pressure } \\ H_{0} & \text { applied uniform vertical magnetic field } \\ H & \text { heat source (sink) parameter } \\ H_{s x} & \text { local heat source (sink) parameter } \\ k & \text { thermal conductivity } \\ P r & \text { Prandtl number } \\ Q & \text { Chandrasekhar number } \\ Q_{s} & \text { heat source parameter } \\ Q_{x} & \text { local Chandrasekhar number } \\ t & \text { fluid temperature of the moving sheet } \\ t_{\mathrm{w}} & \text { wall temperature } \\ t_{\infty} & \text { temperature far away from the sheet } \\ u, v & \text { velocity components along } x \text { and } y \\ & \text { direction } \\ U, V & \text { non-dimensional velocity components along } x \\ \mathrm{~V} & \begin{array}{l}\text { and } y \text { direction } \\ \text { variable viscosity parameter }\end{array}\end{array}$

$x$ flow directional co-ordinate along the stretching sheet

$y \quad$ distance normal to the stretching sheet

$X, Y$ dimensionless co-ordinates

$v \quad$ kinematic viscosity

$\mu \quad$ dynamic viscosity

$\mu_{m} \quad$ magnetic permeability

$\theta$ dimensionless temperature in PEST case

$\phi \quad$ dimensionless temperature in PEHF case

$\rho$ density of the fluid

$\sigma \quad$ electrical conductivity

$\psi$ dimensionless stream function

Subscripts

$m$ magnetic quantity

$w \quad$ wall temperature

$\infty \quad$ ambient temperature condition

$\theta$ non-dimensional temperature in PEST

$\phi \quad$ non-dimensional temperature in PEHF 


\section{INTRODUCTION}

Flows due to a continuously moving surface are encountered in several important engineering applications .viz, in the polymer processing unit of a chemical engineering plant, annealing of copper wires, glass fiber and drawing of plastic films. Sakiadis (1961 a, b, c) initiated the theoretical study of these applications by considering the boundary layer flow over a continuous solid surface moving with constant speed. This problem was extended by Erickson et al. (1969) to the case where the transverse velocity at the moving surface is nonzero with heat and mass transfer in the boundary layer accounted for.

Crane (1970) studied the steady two-dimensional boundary layer flow caused by the stretching sheet, which moves in its own plane with a velocity which varies linearly with the axial distance. There after various aspects of the above boundary layer problem on continuous moving surface were considered by many researchers (Vleggar (1977), Gupta and Gupta (1977), Grubka and Bobba (1985), Chen and Char (1988) Kumaran and Ramanaiah (1996), Siddheshwar et al. (2005) and Sekhar and Chethan (2010)).

Many metallurgical processes involve the cooling of continuous strips or filaments by drawing them through a quiescent fluid. During this process of drawing the strips are sometimes stretched. The properties of final product depend on the rate of cooling. Pavlov (1974) examined the flow of an electrically conducting fluid caused solely by the stretching of an elastic sheet in the presence of a uniform magnetic field. Chakrabarthi and Gupta (1979) considered the flow and heat transfer of an electrically conducting fluid past a porous stretching sheet. Anderson (1992) presented an analytical solution of the magnetohydrodynamic flow using a similarity transformation for the velocity and temperature fields. In all the above mentioned studies the physical properties of the ambient fluid were assumed to be constants. However, it is well known that these physical properties of the ambient fluid may change with temperature (Herwig and Wickern (1986), Takhar et al. (1991), Pop et al. (1992), Subhash Abel et al. (2002), Pantokratoras (2004), Ali (2006), Andersson and Aaresth (2007), Prasad et al. (2009), Sekhar and Chethan (2010)).

Magyari and Keller (2000) studied the heat and mass transfer on the boundary layer flow due to an exponentially stretching surface. Elbashbeshy (2001) added new dimension to the study on exponentially stretching surface. Partha et al. (2004) have examined the mixed convection flow and heat transfer from an exponentially stretching vertical surface in quiescent liquid using a similarity solution. Heat and mass transfer in a viscoelastic boundary layer flow over an exponentially stretching sheet were investigated by Khan and Sanjayanand (2005; 2006). Sajid and Hayat (2008) considered the influence of thermal radiation on the boundary layer flow due to an exponentially stretching sheet. Sekhar and Chethan (2012) analyzed the flow and heat transfer due to an exponentially stretching continuous surface in the presence of Boussinesq-Stokes suspension. Siddheshwar et al. (2014) extended this problem by including the effect of the transverse magnetic field. In the present work, we study the boundary layer flow behavior and heat transfer of a Newtonian fluid past an exponentially stretching sheet, when viscosity is a function of temperature and in the presence of external magnetic field.

\section{MATHEMATICAL FORMULATION}

We consider a steady, two-dimensional boundary layer flow of an incompressible, weakly electrically conducting Newtonian fluid due to a stretching sheet. The liquid is at rest and the motion is affected by pulling the sheet at both ends with equal force parallel to the sheet and with speed $u$, which varies exponentially with the distance $\mathrm{x}$ from the origin.

The boundary layer equations governing the flow and heat transfer in a Newtonian fluid over a stretching sheet, assuming that the viscous dissipation is negligible, are

$$
\frac{\partial u}{\partial x}+\frac{\partial v}{\partial y}=0
$$

$u \frac{\partial u}{\partial x}+v \frac{\partial u}{\partial y}=\frac{\partial}{\partial y}\left\{\frac{\mu(t)}{\rho} \frac{\partial u}{\partial y}\right\}-\frac{\mu_{m}{ }^{2} \sigma H_{0}{ }^{2}}{\rho} u$,

$u \frac{\partial t}{\partial x}+v \frac{\partial t}{\partial y}=\frac{k}{\rho C_{p}} \frac{\partial^{2} t}{\partial y^{2}}+Q_{s}\left(t-t_{\infty}\right)$.

Here $u$ and $v$ are the components of the liquid velocity in the $x$ and $y$ directions, respectively, $t$ is the temperature of the sheet, $t_{\infty}$ is the temperature of the fluid far away from the sheet, $\mu$ is the dynamic viscosity, $\mu_{m}$ is the magnetic permeability, $H_{0}$ is the applied magnetic field, $\rho$ is the density, $\sigma$ is the electric conductivity of the fluid, $k$ is the thermal conductivity, $C_{p}$ is the specific heat at constant pressure and $Q_{s}$ is the heat source coefficient.

The coefficient of viscosity is assumed to be a reciprocal function of temperature and it is of the form

$$
\mu(t)=\frac{\mu_{\infty}}{1+\delta\left(t-t_{\infty}\right)} .
$$

If $\frac{1}{\mu}$ is expanded in Taylor's series about $t=t_{\infty}$ then the scalar appearing in the above expression can be written as $\delta=\left[\frac{\partial}{\partial t}\left(\frac{1}{\mu}\right)\right]_{t=t_{\infty}}$.

Here $\mu_{\infty}$ is the coefficient of viscosity far away from the sheet

The following boundary conditions are 
P. G. Siddheshwar et al. / JAFM, Vol. 7, No. 2, pp. 367-374, 2014.

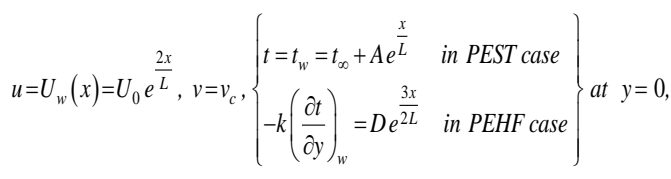

$u \rightarrow 0, T \rightarrow T_{\infty}$ as $y \rightarrow \infty$.

where

$$
t_{w}-t_{\infty}=\left\{\begin{array}{ll}
A e^{\frac{x}{L}} & \text { in PEST case } \\
\frac{D L}{k \sqrt{R e}} e^{\frac{x}{2 L}} & \text { in PEHF case }
\end{array}\right\}
$$

where $t_{w}$ is the temperature of the sheet, $U_{0}$ is the reference velocity and $L$ is the reference length.

We now make the equations and boundary conditions dimensionless using the following definition:

$$
(X, Y)=\frac{(x, y \sqrt{R e})}{L},\left(U, V, V_{c}\right)=\frac{\left(u, v \sqrt{R e}, v_{c} \sqrt{R e}\right)}{U_{0}}, T=\frac{t-t_{\infty}}{\Delta t}
$$

where $R e=\frac{U_{0} L}{v}$ is the Reynolds number and $\Delta t=t_{w}-t_{\infty}$ is the sheet-liquid temperature difference.

The boundary layer Eqs. (2.1) to (2.3) on using Eq. (2.5) take the following form.

$\frac{\partial U}{\partial X}+\frac{\partial V}{\partial Y}=0$

$U \frac{\partial U}{\partial X}+V \frac{\partial V}{\partial Y}=-\frac{\mathrm{V}}{(1+\mathrm{V} T)^{2}} \frac{\partial T}{\partial Y} \frac{\partial U}{\partial Y}+\frac{1}{(1+\mathrm{V} T)} \frac{\partial^{2} U}{\partial Y^{2}}-Q U$,

$U \frac{\partial T}{\partial X}+V \frac{\partial T}{\partial Y}+U T=\frac{1}{P r} \frac{\partial^{2} T}{\partial Y^{2}}+H_{S} T$

where

$\mathrm{V}=\delta \Delta t$ is the variable viscosity parameter,

$Q=\frac{\mu_{m}^{2} \sigma H_{0}^{2}}{\alpha}$ is the Chandrasekhar number,

$\operatorname{Pr}=\frac{\mu C_{p}}{k}$ is the Prandtl number and

$H_{s}=\frac{Q_{s}}{\alpha}$ is the heat source (sink) parameter.

The boundary conditions (2.4) take the form

$U=e^{X}, V=V_{c^{\prime}},\left\{\begin{array}{lc}T=1 & \text { in } \\ \text { PEST } \\ \frac{\partial T}{\partial Y}=-e^{X} & \text { in PEHF }\end{array}\right\}$ at $Y=0$,

$U \rightarrow 0, T \rightarrow 0$ as $Y \rightarrow \infty$.

We introduce the stream function $\psi(X, Y)$ as:

$U=\frac{\partial \psi}{\partial Y}, \quad V=-\frac{\partial \psi}{\partial X}$,
Using Eq. (2.10), the boundary layer equations Eqs. (2.7) and (2.8) can be written as

$$
\begin{aligned}
& (1+\mathrm{V} T) \frac{\partial^{3} \psi}{\partial Y^{3}}-\mathrm{V} \frac{\partial T}{\partial Y} \frac{\partial^{2} \psi}{\partial Y^{2}}+(1+\mathrm{V} T)^{2} \frac{\partial \psi}{\partial X} \frac{\partial^{2} \psi}{\partial Y^{2}} \\
& -(1+\mathrm{V} T)^{2} \frac{\partial \psi}{\partial Y} \frac{\partial^{2} \psi}{\partial X \partial Y}-(1+\mathrm{V} T)^{2} Q \frac{\partial \psi}{\partial Y}=0, \\
& \frac{\partial \psi}{\partial Y} \frac{\partial T}{\partial X}-\frac{\partial \psi}{\partial X} \frac{\partial T}{\partial Y}+U T=\frac{1}{P r} \frac{\partial^{2} T}{\partial Y^{2}}+H_{S} T .
\end{aligned}
$$

The corresponding boundary conditions in terms of the stream function can be written as

$\frac{\partial \psi}{\partial Y}=e^{X}, \frac{\partial \psi}{\partial X}=-V_{c},\left\{\begin{array}{lr}T=1 & \text { in PEST } \\ \frac{\partial T}{\partial Y}=-e^{X} & \text { in PEHF }\end{array}\right\}$ at $Y=0$,

$\frac{\partial \psi}{\partial Y} \rightarrow 0, T \rightarrow 0$ as $Y \rightarrow \infty$.

The following similarity transformation will now be used on Eqs. (2.11) and (2.12).

$$
\begin{aligned}
& \psi(x, \eta)=f(\eta) e^{X}, T(X, Y)=\left\{\begin{array}{l}
\theta(\eta) \text { in PEST case } \\
\phi(\eta) \text { in PEHF case }
\end{array}\right\}, \\
& \eta=Y e^{X} .
\end{aligned}
$$

Using the transformations given by Eq. (2.14) in Eqs. (2.11) and (2.12), we get the following boundary value problems.

(i) PST:

$$
\begin{aligned}
& (1+\mathrm{V} \theta) f^{\prime \prime \prime}-\mathrm{V} \theta^{\prime} f^{\prime \prime}+(1+\mathrm{V} \theta)^{2}\left(f f^{\prime \prime}-2 f^{\prime 2}-Q_{x} f^{\prime}\right)=0 \\
& \theta^{\prime \prime}+\operatorname{Pr} f \theta^{\prime}-\operatorname{Pr} f^{\prime} \theta+\operatorname{Pr}_{s x} \theta=0, \\
& f(0)=-V_{c x}, f^{\prime}(0)=1, \theta(0)=1, \\
& f^{\prime}(\infty) \rightarrow 0, \theta(\infty) \rightarrow 0 .
\end{aligned}
$$

(ii) PHF:

$$
\begin{aligned}
& (1+\mathrm{V} \Phi) f^{\prime \prime \prime}-\mathrm{V} \Phi^{\prime} f^{\prime \prime}+(1+\mathrm{V} \Phi)^{2}\left(f f^{\prime \prime}-2 f^{\prime 2}-Q_{x} f^{\prime}\right)=0 \\
& \phi^{\prime \prime}+\operatorname{Pr} f \phi^{\prime}-\operatorname{Pr} f^{\prime} \phi+\operatorname{Pr} H_{s x} \phi=0, \\
& f(0)=-V_{c x}, f^{\prime}(0)=1, \Phi^{\prime}(0)=-1, \\
& f^{\prime}(\infty) \rightarrow 0, \Phi(\infty) \rightarrow 0 .
\end{aligned}
$$

where $V_{c x}=\frac{V_{c}}{e^{X}}$ is the local suction/injection parameter, $Q_{x}=\frac{Q}{e^{2 X}}$ is the local Chandrasekhar number and $H_{s x}=\frac{Q_{s} L}{U_{0} e^{2 X}}$ is the local heat source (sink) parameter.

Here, primes denote the differentiation with respect to $\eta$. 


\section{METHOD OF SOLUTION}

The boundary value problems due to an exponential stretching sheet are solved numerically by shooting method. We adopt the shooting method with RungeKutta-Fehlberg-45 scheme to solve the boundary value problems in PEST and PEHF cases mentioned in the previous section. The coupled non-linear Eqs. (2.15) and (2.16) in the PEST case are transformed to a system of five first order differential equations as follows:

$$
\begin{aligned}
& \frac{d f_{0}}{d Y}=f_{1}, \\
& \frac{d f_{1}}{d Y}=f_{2}, \\
& \frac{d f_{2}}{d Y}=\frac{\mathrm{V} \theta_{1}}{\left(1+\mathrm{V} \theta_{0}\right)} f_{2}+\left(1+\mathrm{V} \theta_{0}\right)\left(-f_{0} f_{2}+2 f_{1}^{2}+Q_{x} f_{1}\right), \\
& \frac{d \theta_{0}}{d Y}=\theta_{1}, \\
& \frac{d \theta_{1}}{d Y}=\operatorname{Pr} f_{1} \theta_{0}-\operatorname{Pr} f_{0} \theta_{1}-\operatorname{Pr} H_{s x} \theta_{0} .
\end{aligned}
$$

Subsequently the boundary conditions in Eq. (2.17) take the form

$$
\begin{aligned}
& f_{0}(0)=-V_{c x}, f_{l}(0)=1, f_{l}(\infty) \rightarrow 0, \\
& \theta_{0}(0)=1, \theta_{0}(\infty) \rightarrow 0 . \\
& \text { Here } f_{0}=f(\eta) \text { and } \theta_{0}=\theta(\eta) .
\end{aligned}
$$

A forementioned boundary value problem is converted into an initial value problem by choosing the values of $f_{2}(0)$ and $\theta_{1}(0)$ appropriately.

Resulting initial value problem is integrated using the fourth order Runge-Kutta method. NewtonRaphson method is implemented to correct the guess values of $f_{2}(O)$ and $\theta_{l}(0)$. In solving Eqs. (2.21) subjected to boundary conditions (2.22) the appropriate ' $\infty$ ' is determined through the actual computation. Same procedure is adopted to solve the boundary layer equations in PEHF case.

\section{RESULTS AND DISCUSSION}

The hydromagnetic boundary layer flow and heat transfer in a weakly electrically conducting Newtonian fluid past an exponentially stretching sheet with temperature dependent viscosity are investigated. Numerical solution of the problem is obtained by shooting method.

Figures 1 to 3 are plots of the stream lines for various values of the parameters $\psi, H_{s x}, \mathrm{~V}, V_{c x}, P r$ and $Q_{x}$. Quite clearly we see that the effect of $\psi$ and $\mathrm{V}$ is to push the dynamics away from the stretching sheet and away from the slit at $(0,0)$. The effect of suction $\left(V_{c x}<0\right)$ and Prandtl number $P r$ is to bring the region of dynamics closer to the slit. The effect of injection $\left(V_{c x}>0\right)$ is similar to $\mathrm{V}$ and so is the effect of $Q_{x}$.

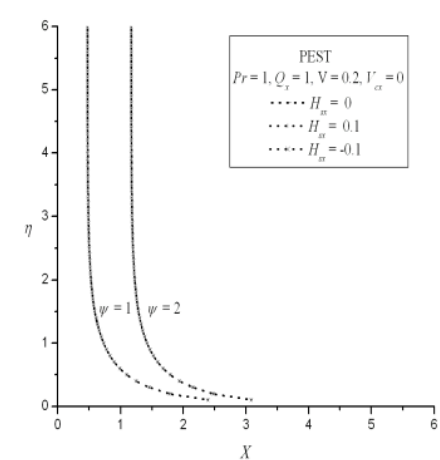

(a)

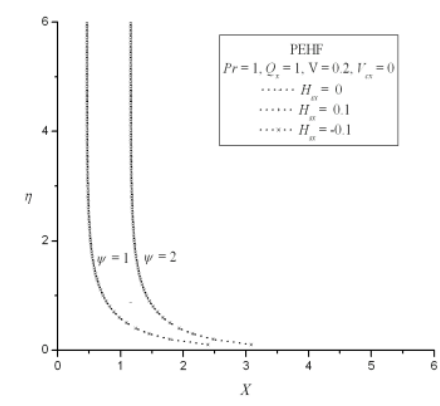

(b)

Fig. 1. Plot of stream lines for different values of $\psi$ and $H_{s x}$ in PEST and PEHF cases.

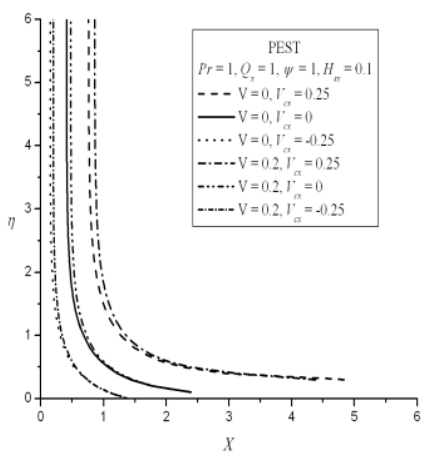

(a)

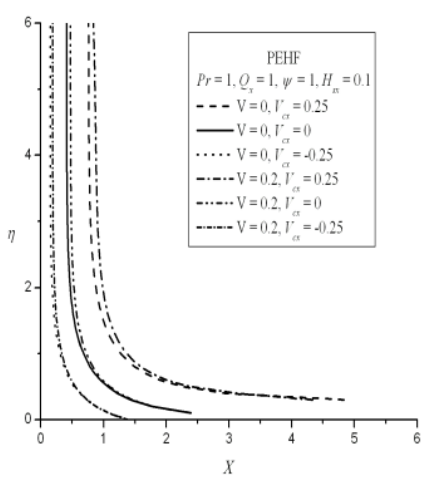

(b)

Fig. 2. Plot of stream lines for different values of $\mathrm{V}$ and $V_{c x}$ in PEST and PEHF cases. 


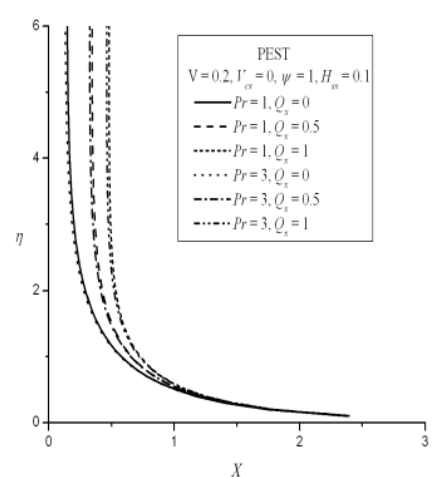

(a)

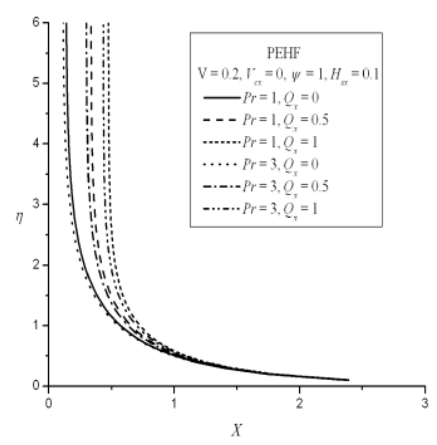

(b)

Fig. 3. Plot of stream line for different values of $\mathrm{Pr}$ and $Q_{x}$ in PEST and PEHF cases.

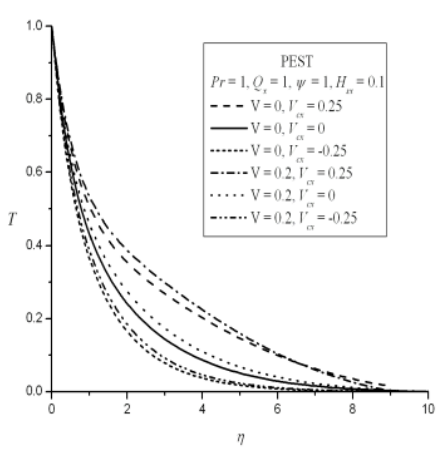

(a)

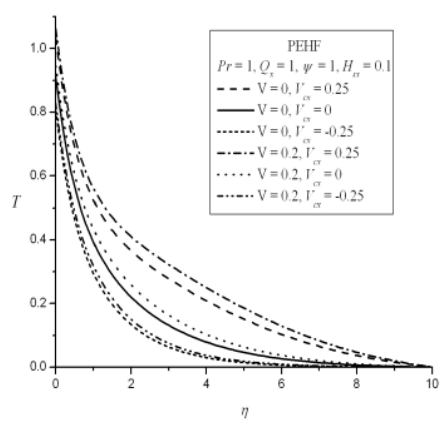

(b)

Fig. 4. Plot of temperature profiles $(T)$ versus $Y$ for different values of $\mathrm{V}$ and $V_{c}$ in PEST and PEHF cases.
Figure 4 demonstrates the effect of variable viscosity parameter $\mathrm{V}$ and suction/injection parameter $V_{c}$ on the temperature distribution. The effect of $\mathrm{V}$ and injection $\left(V_{c x}>0\right)$ is to increase the thermal boundary layer thickness whereas suction $\left(V_{c x}<0\right)$ reduces it.

The effect of Chandrasekhar number $Q_{x}$ and Prandtl number $P r$ on temperature profiles are shown in Fig.5. It is noticed that the effect of $Q_{x}$ is to increase the temperature in the boundary layer. This is because of the fact that the introduction of transverse magnetic field to an electrically conducting fluid gives rise to a resistive type of force known as Lorentz force. This force has the tendency to slow down the motion of the fluid in the boundary layer and to increase the temperature profile. Also, the effect of increasing values of Prandtl number is decrease the temperature distribution in the flow region.

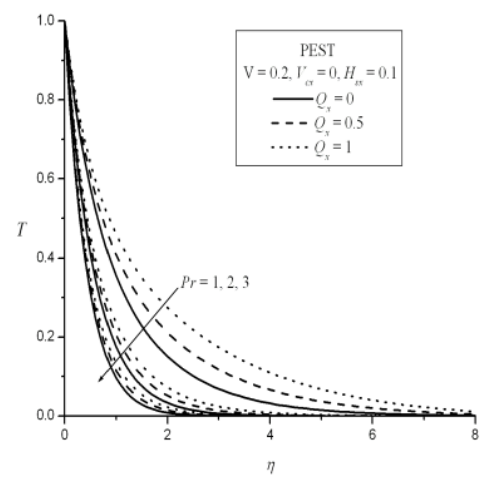

(a)

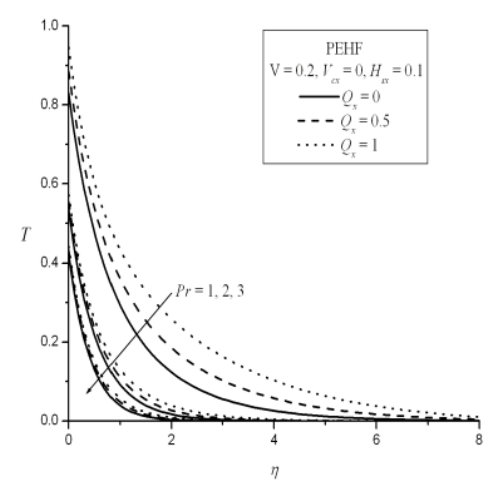

(b)

Fig. 5. Plot of stream lines for different values of $Q_{x}$ and $P r$ in PEST and PEHF cases.

It is observed that the effect of heat source $\left(H_{S x}>0\right)$ in the boundary layer generates energy which causes the temperature to increase, while the presence of heat sink $\left(H_{s x}<0\right)$ in the boundary layer absorbs the energy which causes the temperature to decrease. These behaviors are seen in Fig. 6. 


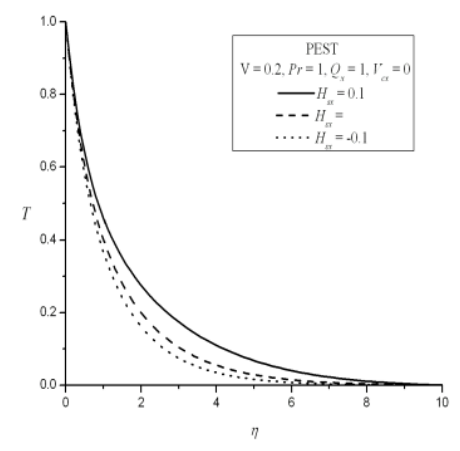

(a)

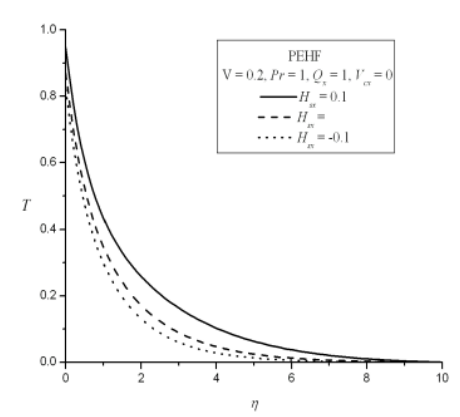

(b)

Fig. 6. Plot of temperature profiles for different values of $H s_{x}$ in PEST and PEHF cases.

In order to validate our results, we have compared the rate of heat transfer $-\theta^{\prime}(0)$ in the absence of variable viscosity $(\mathrm{V}=0)$, Chandrasekhar number $\left(Q_{x}=0\right)$ and heat source/sink parameter $\left(H_{S x}=0\right)$ with the published results and found them to be in good agreement (see Table 1).

Table 1 Comparison of values of skin friction $-f^{\prime \prime}(0)$ for various values of $V_{c x}$ with $\mathrm{V}=Q_{x}=H_{s x}=0$ in case of exponential stretching

\begin{tabular}{|c|c|c|}
\hline$V_{c x}$ & $\begin{array}{c}\text { Elbashbeshy } \\
(2001)\end{array}$ & Present study \\
\hline 0 & 1.28181 & 1.281816 \\
-0.2 & 1.37889 & 1.378894 \\
-0.4 & 1.4839 & 1.484389 \\
-0.6 & 1.59824 & 1.598242 \\
\hline
\end{tabular}

Thus suction can be used as a means to get better cooling of the continuous sheet. Larger the value of $\mathrm{Pr}$, larger is the magnitude of the wall temperature gradient. The wall temperature gradient in the PEST case decreases but the wall temperature in the PEHF case increases as $H_{s x}$ increases from a negative value to a positive value. Therefore PEHF boundary conditions are better suited than PEST boundary conditions in cooling the stretching sheet relatively faster as can be seen from the tabulated values.
Table 2 Values of wall temperature gradient and wall temperature for different values of $\mathrm{V}, V_{c x}, Q_{x}$, $\operatorname{Pr}$ and $H_{s x}$

\begin{tabular}{|c|c|c|c|}
\hline \multicolumn{2}{|c|}{ Parameters } & $\begin{array}{c}\text { Wall } \\
\text { temperature } \\
\text { gradient } \\
-\theta^{\prime}(0)\end{array}$ & $\begin{array}{c}\text { Wall } \\
\text { temperature } \\
\phi(0)\end{array}$ \\
\hline \multicolumn{4}{|c|}{$\operatorname{Pr}=1, Q_{x}=1, H_{s x}=0.1, V_{c x}=0$} \\
\hline \multirow{3}{*}{$\mathrm{V}$} & 0 & 1.098308 & 0.910492 \\
\hline & 0.1 & 1.076160 & 0.927866 \\
\hline & 0.2 & 1.054422 & 0.946307 \\
\hline \multicolumn{4}{|c|}{$\mathrm{V}=0.2, \operatorname{Pr}=1, Q_{x}=1, H_{s x}=0.1$} \\
\hline \multirow{3}{*}{$V_{c x}$} & 0.25 & 0.929581 & 1.169142 \\
\hline & 0 & 1.054422 & 0.946307 \\
\hline & -0.25 & 1.199609 & 0.828875 \\
\hline \multicolumn{4}{|c|}{$\mathrm{V}=0.2, V_{c x}=0, \operatorname{Pr}=1, H_{s x}=0.1$} \\
\hline \multirow{3}{*}{$Q_{x}$} & 0 & 1.199513 & 0.830559 \\
\hline & 0.5 & 1.124547 & 0.886122 \\
\hline & 1 & 1.054422 & 0.946307 \\
\hline \multicolumn{4}{|c|}{$\mathrm{V}=0.2, V_{c x}=0, Q_{x}=1, H_{s x}=0.1$} \\
\hline \multirow{3}{*}{$\operatorname{Pr}$} & 1 & 1.124547 & 0.886122 \\
\hline & 2 & 1.788236 & 0.554558 \\
\hline & 3 & 2.289972 & 0.433010 \\
\hline & \multicolumn{3}{|c|}{$\mathrm{V}=0.2, V_{c x}=0, P r=1, Q_{x}=1$} \\
\hline \multirow{3}{*}{$H_{s x}$} & 0.1 & 1.054422 & 0.946307 \\
\hline & 0 & 1.145893 & 0.869503 \\
\hline & -0.1 & 1.213054 & 0.820987 \\
\hline
\end{tabular}

\section{CONCLUSION}

1. The effect of variable viscosity parameter $\mathrm{V}$ is to push the dynamics away form the stretching sheet.

2. Increase in suction/injection parameter $V_{c x}$ will blow up stream lines.

3. The effect of variable viscosity parameter $\mathrm{V}$ is to increase the temperature in the boundary layer.

4. The temperature in the boundary layer decreases (increases) due to suction (injection).

5. The effect of Prandtl number is to decrease the thermal boundary layer thickness.

6. The heat source parameter $H_{s x}$ increases the heat transfer in both PEST and PEHF cases and the opposite is observed in the case of a sink.

\section{REFERENCES}

Sakiadis, B. C. (1961a). Boundary-layer behavior on continuous solid surfaces I: The boundary layer on a equations for two dimensional and axisymmetric flow, AIChE J 7, 26-28. 
Sakiadis, B. C. (1961b). Boundary-layer behavior on continuous solid surfaces II: The boundary layer on a continuous flat surface, AIChE $J$, 221-225.

Sakiadis, B. C. (1961c). Boundary-layer behavior on continuous solid surfaces III: The boundary layer on a continuous cylindrical surface, AIChE J 7 (1961c) 467.

Erickson, L.E., Fan, L.T. and Fox, V.G. (1969). Heat and mass transfer on a moving continuous flat plate with suction or injection, Ind. Engg. Chem. Fund. 5, 19-25.

Crane, L. J. (1970). Flow past a stretching plate, ZAMP 21, 645.

Vleggar, J. (1977), Laminar boundary layer behavior on continuous accelerating surfaces, Chem. Eng. Sci., 32, 1517-1525.

Gupta, P.S. and Gupta, A.S. (1977). Heat and mass transfer on a stretching sheet with suction or blowing, Canad. J. of Chem. Engg., 55, 744746.

Grubka, L. J. and Bobba, K. M. (1985), Heat transfer characteristics of a continuous stretching surface with variable temperature, ASME J. Heat Transfer, 107, 248-250.

Chen, C. K. and Char, M. I. (1988), Heat transfer of a continuous stretching surface with suction or blowing, J. Math. Anal. Appl., 135, 568-580.

Kumaran, V. and Ramanaiah, G. (1996). A note on the flow over a stretching sheet, Acta Mech. 116, 229-233.

Siddheshwar, P. G, Mahabaleshwar, U. S. (2005), Effects of radiation and heat source on MHD flow of a viscoelastic liquid and heat transfer over a stretching sheet, Int. J. Nonlinear Mech., 40, 807-820.

Sekhar, G. N. and Chethan, A. S. (2010), Flow and heat transfer of quadratic stretching sheet in a Boussinesq-Stokes suspension, International Journal of Applied Mechanics and Engineering, 16(4), 1109-1128.

Pavlov, K. B. (1974), Magneto hydro dynamic flow of an incompressible viscous fluid caused by deformation of a plane surface, Magnitanaya Gidrodinamika (USSR), 4, 146-147.
Chakrabarthi, A. and Gupta, A. S. (1979), Hydrodynamic flow and heat transfer over a stretching sheet, Quart. Appl. Math., 37, 73-78.

Anderson, H. I. (1992), MHD flow of a visoelastic fluid past a stretching surface, Acta Mech., 95, 227-230.

Herwig, H. and Wickern, G. (1986), The effect of variable properties on laminar boundary layer flow, Warme Stoffubert, 20, 47-57.

Takhar, H. S. Nitu, S. and Pop, I. (1991), Boundary layer flow due to a moving plate: variable fluid properties. Acta. Mech., 90, 37-42.

Pop, I. Gorla, R. S. R. and Rashidi, M. (1992), The effect of variable viscosity on flow and heat transfer to a continuous moving flat plate, Int. J. Eng. Sci., 30, 1-6.

Subhash Abel, M. Khan, S. K. and Prasad, K. V. (2002), Study of viscoelastic fluid flow and heat transfer over a stretching sheet with variable fluid viscosity, Int. J. Non-Linear Mech., 27, 81-88.

Pantokratoras, A. (2004), A further results on the variable viscosity on the flow and heat transfer to continuous moving flat plate, Int. J. Eng. Sci., 42, 1891-1896.

Ali, M. E. (2006). The effect of variable viscosity on mixed convection heat transfer along a vertical moving surface, Int. J. Thermal Sci., $45,60-69$.

Andersson, H. I. and Aarseth, J. B. (2007), Sakiadis flow with variable fluid properties: revisited, Int. J. Eng. Sci., 45, 554-561.

Prasad, K. V. Dulal Pal, and Datti, P. S. (2009), MHD power law fluid flow and heat transfer over non-isothermal stretching sheet, Comm. Non-Linear Sci. Numer. Simulat., 14, 21782189.

Sekhar, G. N. and Chethan, A. S. (2010), Heat transfer in a stretching sheet problem in electrically conducting Newtonian liquids with temperature dependent viscosity, Proceedings of the ASME 2010 International Mechanical Engineering Congress \& Exposition IMECE2010, British Colombia, Vancouver, Canada. 
P. G. Siddheshwar et al. / JAFM, Vol. 7, No. 2, pp. 367-374, 2014.

Magyari, E. and Keller, B. (2000), Heat and mass transfer in the boundary layers on an exponentially stretching continuous surface, Journal of Physics D: Applied Physics, 32, 577-585.

Elbashbeshy, E. M. A. (2001), Heat transfer over an exponentially stretching continuous surface with suction, Arch. Mech., 53(6), 643-651.

Partha, M. K. Murthy, P. and Rajashekhar, G. P. (2004), Effect of viscous dissipation on the mixed convection heat transfer from an exponentially stretching surface, Heat Mass Transfer, 41, 360-366.

Khan, S. K. and Sanjayanand, E. (2005), Viscoelastic boundary layer flow and heat transfer over an exponential stretching sheet, Int. J. Heat and Mass Transfer, 48, 534-542.
Sanjayanand, E. Khan, S. K. (2006), On the heat and mass transfer in a viscoelastic boundary layer flow over an exponentially stretching sheet, Int. J. Therm. Sci., 45, 819-828.

Sajid, M. and Hayat, T. (2008), Influence of thermal radiation on the boundary layer flow due to an exponentially stretching sheet, Int. Comm. Heat Mass Transfer, 35, 347-356.

Sekhar, G. N. and Chethan, A. S. (2012), Flow and heat transfer of an exponential stretching sheet in Boussinesq-Stokes suspension, Int. J. Mathematical Archive, 3(5), 1978-1984.

Sidhheshwar, P. G. Sekhar, G. N. and Chethan, A. S. (2014), MHD flow and heat transfer of an exponential stretching sheet in a BoussinesqStokes suspension, Journal of Applied Fluid Mechanics, 7(1), 169-176. 